(6) OPEN ACCESS

\title{
Screening for suspected coronary heart disease in patients, using integrated serum biochemical indices
}

\author{
Lei Feng, ${ }^{1}$ Chunfang Zhang, ${ }^{2}$ Shiyan Nian, ${ }^{3}$ Yinglu Hao, ${ }^{4}$ Wenbo $\mathrm{Xu}_{1}{ }^{1}$ \\ Xingfeng Zhang, ${ }^{1}$ Jun Zhang, ${ }^{5} \mathrm{Li} \mathrm{Li}^{6}$
}

For numbered affiliations see end of article.

\section{Correspondence to}

Dr Jun Zhang, Department of the First General Surgery,

People's Hospital of Yuxi City, 21 Nieer Road, Yuxi 653100, Yunnan Province, China; zhangjunyxyy@163.com

$\mathrm{LF}, \mathrm{CZ}$ and $\mathrm{SN}$ contributed equally.

Received 12 July 2015 Revised 16 August 2015 Accepted 25 August 2015

Published Online First 25 September 2015

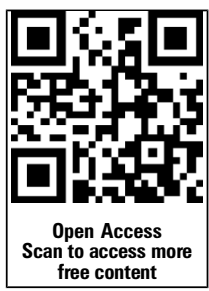

CrossMark

To cite: Feng $L$, Zhang $C$,

Nian S, et al. J Epidemiol

Community Health

2016:70:195-201.

\section{ABSTRACT}

Background Many serum biochemical indices have been found to be associated with coronary heart disease (CHD); however, few studies have evaluated the value on screening CHD of the integrated serum biochemical indices.

Methods In this study, 627 healthy controls and 1049 patients with CHD were recruited to develop CHD screening models for males and females using unconditional logistic regression. The performance of the screening models was evaluated by areas under the receiver operating characteristic (ROC) curves (AUCs), and externally validated in another population comprised of 190 healthy controls and 246 patients with CHD. Results Backward stepwise variable selection showed that increasing age, total cholesterol (TC), logarithmtransformed homocysteine (InHCY), logarithmtransformed $\gamma$-glutamyl transpeptidase (InGGT), and decreasing uric acid, logarithm-transformed triglyceride, apolipoprotein A (apoA) and apolipoprotein B (apoB), increased the detection of CHD in males. In comparison, increasing age, TC, InHCY, InGGT and high-density lipoprotein cholesterol versus low-density lipoprotein cholesterol, and decreasing apoA, apoB, logarithm transformed lipoprotein $(A)$ and logarithm transformed total bilirubin, increased the detection of CHD in females. The AUCs for the screening models for males and females were $0.958(95 \% \mathrm{Cl} 0.946$ to 0.969$)$ and 0.986 (95\% Cl 0.977 to 0.994$)$, respectively. The performance of the screening models was further evaluated in external validation samples, the AUCs for males and females were 0.907 and 0.992 , respectively. Conclusions Our study suggests that integrated serum biochemical indices may be used to screen for suspected CHD in participants.

\section{INTRODUCTION}

Coronary heart disease (CHD) remains a persistent public health burden worldwide and is the second leading cause of cardiovascular death in the Chinese population. ${ }^{12}$ In CHD, the supply of blood, oxygen and nutrients to the heart muscle is reduced because of the build-up of a waxy substance, known as a plaque, (ie, atherosclerosis), in the coronary arteries. ${ }^{3}$ CHD develops when the coronary arteries become damaged or diseased; over time, plaques can harden or rupture, narrowing the coronary arteries due to the formation of blood clots, and reducing or blocking the flow of blood to the heart. ${ }^{4} 5$ The decrease in blood flow may cause angina, shortness of breath, or other signs and symptoms of CHD. ${ }^{6}$ Complete blockage can cause a myocardial infarction or even sudden cardiac death.
Atherosclerosis is now recognised as a complex inflammatory disorder of the coronary arteries. ${ }^{8}$ When the arterial endothelium encounters certain endovascular substances such as proinflammatory cytokines, the products of glycoxidation, dyslipidaemia or vasoconstrictor hormones, endothelial cells augment the expression of adhesion molecules that promote the adherence of blood leucocytes to the inner surface of the arterial wall. ${ }^{9}{ }^{10}$ Adherent mononuclear phagocytes and $\mathrm{T}$ lymphocytes communicate with the cells of the arterial wall endothelium and smooth muscle cells (SMCs), and trigger an exchange of messages among the various cell types, leading to inflammation in the early atheroma. ${ }^{6}{ }^{11}$ Lipid mediators such as prostanoids, leucotrienes, histamine, cytokines and complement components participate in this pathophysiological process. ${ }^{6}$ Subsequently, SMCs migrate from the tunica media to the intima. ${ }^{12}$ These cells proliferate and elaborate a rich and complex extracellular matrix in response to various oxidative, haemodynamic, inflammatory and autoimmune signals. ${ }^{6}$ Certain constituents of the extracellular matrix (eg, proteoglycans) bind lipoproteins, prolonging their residence in the intima, and rendering them more susceptible to oxidative modification and glycation. ${ }^{13}$ These products of lipoprotein modification, including oxidised phospholipids and advanced glycation end products, sustain and propagate the inflammatory response. ${ }^{14}$ As the lesion progresses, calcification may occur. ${ }^{15}$ In addition to proliferation, apoptotic cell death occurs in the established atherosclerotic lesion. ${ }^{16}$ The death of lipid-laden macrophages leads to the extracellular deposition of tissue factor, some in particulate form. ${ }^{6}{ }^{16}$ The accumulating extracellular lipids in the intima can coalesce, forming the core of the atherosclerotic plaque. ${ }^{6}$

Epidemiological studies have identified a series of risk factors associated with CHD. ${ }^{17}$ Age, sex, family history and ethnicity are classic unmodifiable risk factors; ${ }^{18}$ of these, age is the strongest predictor of adverse cardiovascular outcomes. ${ }^{19}$ Although cardiovascular disease is the biggest cause of mortality in women, men have about twice the total morbidity and mortality, compared to women. ${ }^{20}$ Family history is a significant contributing factor to CHD. ${ }^{21}$ Ethnicity is a well-recognised risk factor, with a higher prevalence of cardiovascular disease in South Asian and black populations. ${ }^{22}$ Hypertension, dyslipidaemia and diabetes are classic modifiable risk factors. ${ }^{17}$ Systolic and diastolic blood pressures are strongly positively associated with cardiovascular disease; patients with CHD can benefit from antihypertensive 
therapy. $^{23} 24$ Cholesterol and triglyceride abnormalities constitute almost half the population-attributable risk. ${ }^{25}$ Patients with diabetes mellitus are considered to be at high risk of $\mathrm{CHD}$ regardless of other factors; ${ }^{26}$ increasing glycaemic levels are positively correlated with vascular complications. ${ }^{27}$ Smoking, alcohol abuse, obesity and high dietary intake of high-fat, highcarbohydrate and high-calorie diets are behavioural risk factors associated with CHD. ${ }^{17}$ Recently, a number of new biomarkers involved in the pathophysiology of CHD have been described. ${ }^{28}$ Genome-wide association studies have also identified a number of genetic cardiovascular risk biomarkers. ${ }^{17}$

Awareness of the importance of blood biochemical markers is growing. ${ }^{29}$ CHD may change the estimated glomerular filtration rate derived from serum creatinine measurement. ${ }^{30}$ Other blood biochemical markers, including homocysteine (HCY), ${ }^{31}$ uric acid (UA), ${ }^{32}$ microalbuminuria and cystatin $\mathrm{C},{ }^{33} 34$ are considered to change in patients with $\mathrm{CHD}$ as well; however, they are confounded by the relationship with other risk factors such as smoking. ${ }^{17}$ As research on CHD has progressed, scientists have started to combine the identified markers in order to produce an index with high screening value. ${ }^{17}$ Specialist societies recommend initiating preventive treatment of cardiovascular disease on the basis of a person's 10-year risk for CHD. Well-known prognostic models to estimate this risk originate from the Framingham Heart Study, ${ }^{35}$ the Women's Health Study, ${ }^{36}$ the PROCAM (Prospective Cardiovascular Münster) study (37) and the SCORE (Systematic Coronary Risk Evaluation) project (38). These risk-estimation systems were derived from large-scale prospective cohorts and focused on the primary prevention of CHD worldwide. ${ }^{35-38}$ In this study, we aimed to develop a model utilising biochemical markers to screen for suspected CHD in patients with symptoms.

\section{METHODS}

\section{Ethical issues}

This study was conducted according to the principles of the World Medical Association Declaration of Helsinki. The study was approved by the Review Board of the People's Hospital of Yuxi City (Yuxi, China) (approval number: YNYXH2010-0012). All participants provided written informed consent prior to participating in this study. The participants were simultaneously informed of their right to repeal consent by themselves or their kin, caretakers or guardians.

\section{Model developing population}

Patients with CHD were consecutively recruited from Department of Cardiology, People's Hospital of Yuxi City, between September 2010 and July 2013. Patients suspected of having CHD were initially screened based on their symptoms, medical and family histories, risk factors for CHD and a physical examination. Patients' symptoms included (1) heaviness, tightness, pressure and/or pain in the chest behind the breastbone; (2) pain radiating in the arms, shoulders, jaw, neck and/or back; (3) shortness of breath; (4) weakness and fatigue. Patients suspected of having CHD were further diagnosed according to American Heart Association guidelines. All patients with CHD were confirmed to have arteriostenosis $(>50 \%)$ of at least one large epicardial coronary artery, caused by an atheromatous plaque, using coronary angiography.

Unrelated consecutive inpatients, in the department of cardiology for other reasons, were recruited as controls during the same time period. These individuals had no history of CHD and were further evaluated by two or more cardiological tests to exclude latent CHD.
Participants who met the following exclusion criteria were excluded from the study: alcohol abuse; diabetes; history of smoking; evidence of non-coronary atherosclerotic disease; a chronic infectious disease, chronic or acute liver disease, chronic lung disease, chronic kidney disease, chronic wasting disease, malignant tumour, autoimmune disease or xanthelasma.

\section{External validation population}

To test the value of the screening strategy derived from the above modelling population, another group of unrelated consecutive inpatients were recruited from the same department of the hospital in the following year. Inclusion and exclusion criteria for participants with CHD and controls were the same as those of the model deviation population.

\section{Laboratory-based biochemical testing and questionnaire}

A fasting blood sample was collected from each participant via the antecubital vein, in the morning. Serum lipid profiles, including total cholesterol (TC), triglycerides (TG), high-density lipoprotein-C (HDL-C), low-density lipoprotein-C (LDL-C), apolipoprotein (apo)A, apoB, apoE and lipoprotein (a) $\mathrm{Lp}(\mathrm{a})$; indicators of liver function, including $\gamma$-glutamyl transpeptidase (GGT), total bilirubin (TBil), indirect bilirubin (IBil) and direct bilirubin (DBil); indicators of kidney function, including UA; and HCY levels, were measured in the Hospital's laboratory according to routine procedures.

A questionnaire was self-administered by all participants; the items included age, sex, ethnicity, medical history, family history and manifestations of $\mathrm{CHD}$, alongside behavioural risk factors such as smoking, alcohol abuse, obesity and high dietary intake of high-fat, high-carbohydrate and high-calorie diets.

\section{Statistical analysis}

All analyses were performed using SPSS for Windows (V.18). Continuous variables that were normally or approximately normally distributed are presented as the mean $\pm S D$, while those with a skewed distribution are presented as the median (1st and 3 rd quantiles). Univariable analyses were performed using independent $t$ tests or Wilcoxon rank tests, as appropriate. To eliminate multicollinearity between or among variables, collinearity diagnostics were performed before further statistical analysis. Continuous variables that were not normally distributed were natural logarithm-transformed prior to the analysis.

Multiple unconditional logistic regression models were developed for risk estimation. Potentially relevant clinical predictors according to the univariable analysis $(p<0.10)$ were introduced into the starting model and then eliminated manually using the backward step-by-step approach, depending on the largest $\mathrm{p}$ value. All items showing statistical significance at $\mathrm{p}<0.05$ were retained in the final screening model. Internal cross-validation was used to minimise overfitting. The performance of discrimination was evaluated by an area under receiver operating characteristic (ROC) curve (AUC). The screening model was externally validated in the validation population, with AUC calculated. In view of the discrepancies between males and females in previous risk score models, we developed and validated our models by sex.

\section{RESULTS}

\section{Participants included in the model development population}

Data collected from the participants between 1 October 2010, and 31 July 2013, were used to develop the screening model. The characteristics of the participants used for model development are listed in table 1.

The model development population included 1049 patients with CHD, with 664 males and 385 females, aged $63.3 \pm 11.2$ 
Table 1 Description of the participants for model developing by gender

\begin{tabular}{|c|c|c|c|c|}
\hline \multirow[b]{2}{*}{ Variable } & \multicolumn{2}{|l|}{ Male } & \multicolumn{2}{|l|}{ Female } \\
\hline & $\begin{array}{l}\text { Control } \\
(n=400)\end{array}$ & $\begin{array}{l}\text { CHD } \\
(n=664)\end{array}$ & $\begin{array}{l}\text { Control } \\
(n=227)\end{array}$ & $\begin{array}{l}\text { CHD } \\
(n=385)\end{array}$ \\
\hline Age (year) & $45.5 \pm 12.1$ & $63.3 \pm 11.2$ & $43.3 \pm 10.4$ & $62.5 \pm 9.0$ \\
\hline UA $(\mu \mathrm{mol} / \mathrm{L})$ & $404.9 \pm 86.1$ & $387.8 \pm 96.4$ & $282.6 \pm 61.3$ & $323.9 \pm 84.4$ \\
\hline $\mathrm{TC}(\mathrm{mmol} / \mathrm{L})$ & $4.9 \pm 0.9$ & $4.7 \pm 1.0$ & $4.5 \pm 0.8$ & $4.9 \pm 1.1$ \\
\hline TG $(\mathrm{mmol} / \mathrm{L})$ & $1.2(0.9,1.7)$ & $1.6(1.2,2.4)$ & $1.9(1.3,3.1)$ & $1.5(1.2,2.4)$ \\
\hline $\mathrm{HDL}-\mathrm{C}(\mathrm{mmol} / \mathrm{L})$ & $1.3 \pm 0.4$ & $1.1 \pm 0.3$ & $1.6 \pm 0.3$ & $1.2 \pm 0.3$ \\
\hline LDL-C (mmol/L) & $3.0 \pm 0.8$ & $2.8 \pm 1.0$ & $2.7 \pm 0.7$ & $2.7 \pm 0.9$ \\
\hline apoA (g/L) & $1.5 \pm 0.3$ & $1.2 \pm 0.3$ & $1.6 \pm 0.2$ & $1.3 \pm 0.2$ \\
\hline apoB (g/L) & $1.1 \pm 0.2$ & $0.9 \pm 0.3$ & $0.9 \pm 0.2$ & $0.9 \pm 0.3$ \\
\hline $\mathrm{Lp}(\mathrm{a})(\mathrm{mg} / \mathrm{L})$ & $188.0(110.0,361.0)$ & $199.0(96.0,376.0)$ & $180.5(108.5,353.5)$ & $146.5(61.0,283.5)$ \\
\hline $\mathrm{HCY}(\mu \mathrm{mol} / \mathrm{L})$ & $7.1(4.3,9.7)$ & $17.0(12.4,18.9)$ & $11.9(8.6,14.9)$ & $18.3(14.9,21.4)$ \\
\hline TBil $(\mu \mathrm{mol} / \mathrm{L})$ & $11.5(8.9,14.5)$ & $9.9(7.5,13.0)$ & $13.6(10.8,17.6)$ & $12.4(9.2,16.05)$ \\
\hline Dbil $(\mu \mathrm{mol} / \mathrm{L})$ & $2.9(2.3,3.7)$ & $3.5(2.5,4.5)$ & $3.5(2.8,4.5)$ & $3.3(2.4,4.7)$ \\
\hline IBil $(\mu \mathrm{mol} / \mathrm{L})$ & $8.6(6.7,10.8)$ & $6.1(4.5,9.1)$ & $10.0(7.9,13.2)$ & $8.9(5.9,12.1)$ \\
\hline GGT (IU/L) & $15.0(11.0,22.0)$ & $30.5(20.0,49.0)$ & $36.0(21.0,63.5)$ & $38.0(26.0,60.5)$ \\
\hline
\end{tabular}

Normally distributed data were presented as means $\pm \mathrm{SD}$, skewed data were presented as the median (IQR).

apoA, apolipoprotein A; apoB, apolipoprotein B; CHD, coronary heart disease; DBil, direct bilirubin; GGT, $\gamma$-glutamyl transpeptidase; HCY, homocysteine; HDL-C, high-density lipoprotein cholesterol; IBil, indirect bilirubin; LDL-C, low-density lipoprotein cholesterol; Lp(a), lipoprotein(a); TBil, total bilirubin; TC, total cholesterol; TG, triglyceride; UA, uric acid.

and $62.5 \pm 9.0$ years, respectively (table 1 ). The model development population also included 627 controls, with 400 males and 227 females, who had no history of CHD and were further evaluated by two or more cardiological tests to exclude latent CHD (table 1). The mean age (in years) of the control participants was $45.5 \pm 12.1$ for males and $43.3 \pm 10.4$ for females (table 1). The laboratory test variables were not always normally distributed (eg, TG, Lpa, HCY, TBil, DBil, IBil and GGT); these are presented as medians (1st and 3rd quantiles) rather than means \pm SD (table 1 ).

\section{Deprivation of the screening models}

Sex-specific univariate analyses were performed on all available data, to primarily identify variables associated with an increased detection of CHD. These variables included age, UA, TC, logarithm-transformed TG (lnTG), HDL-C, LDL-C, apoA, apoB, logarithm-transformed Lp(a) (lnLPa), logarithm-transformed HCY (lnHCY), logarithm-transformed TBil (lnTBil), logarithm-transformed DBIL (lnDBil), logarithm-transformed IBil (lnIBil) and logarithm-transformed GGT (lnGGT). Our univariate analysis results are given in table 2. Of the male population, age, UA, TC, $\ln$ TG, HDL-C, LDL-C, apoA, apoB, $\operatorname{lnLp}, \operatorname{lnHCY}, \operatorname{lnTBil}, \ln \mathrm{DBil}$ and $\operatorname{lnIBil}$, are the variables associated with an increased diagnosis of CHD (table 2). Of the female population, age, UA, TC, $\operatorname{lnTG}$, HDL-C, LDL-C, apoA, apoB, lnLp, lnHCY, lnTBil, lnIBil and lnGGT, are the variables associated with an increased diagnosis of CHD (table 2). At this stage, the main differences between males and females are variables $\operatorname{lnGGT}$ and $\operatorname{lnDBil}$, lnGGT is significantly associated with $\mathrm{CHD}$ in females but

Table 2 Univariable analysis of predictor candidates by gender

\begin{tabular}{|c|c|c|c|c|c|c|c|c|}
\hline \multirow[b]{2}{*}{ Variable } & \multicolumn{4}{|l|}{ Male } & \multicolumn{4}{|l|}{ Female } \\
\hline & $\begin{array}{l}\text { Control } \\
(n=400)\end{array}$ & $\begin{array}{l}\text { CHD } \\
(n=664)\end{array}$ & $\mathbf{T}$ & p Value & $\begin{array}{l}\text { Control } \\
(n=227)\end{array}$ & $\begin{array}{l}\text { CHD } \\
(n=385)\end{array}$ & $\mathbf{T}$ & p Value \\
\hline Age (year) & $45.5 \pm 12.1$ & $62.2 \pm 11.0$ & 23.02 & $<0.001$ & $43.3 \pm 10.4$ & $64.9 \pm 9.0$ & 26.02 & $<0.001$ \\
\hline $\mathrm{UA}(\mu \mathrm{mol} / \mathrm{L})$ & $404.9 \pm 86.1$ & $375.4 \pm 96.8$ & 5.16 & $<0.001$ & $282.6 \pm 61.3$ & $325.7 \pm 87.9$ & 7.12 & $<0.001$ \\
\hline $\mathrm{TC}(\mathrm{mmol} / \mathrm{L})$ & $4.9 \pm 0.9$ & $4.6 \pm 1.1$ & 5.94 & $<0.001$ & $4.5 \pm 0.8$ & $5.0 \pm 1.3$ & 5.78 & $<0.001$ \\
\hline InTG & $0.7 \pm 0.7$ & $0.5 \pm 0.6$ & 4.50 & $<0.001$ & $0.2 \pm 0.6$ & $0.6 \pm 0.5$ & 9.06 & $<0.001$ \\
\hline $\mathrm{HDL}-\mathrm{C}(\mathrm{mmol} / \mathrm{L})$ & $1.3 \pm 0.4$ & $1.1 \pm 0.3$ & 10.75 & $<0.001$ & $1.6 \pm 0.3$ & $1.2 \pm 0.3$ & 12.61 & $<0.001$ \\
\hline LDL-C (mmol/L) & $3.0 \pm 0.8$ & $2.8 \pm 1.1$ & 3.43 & 0.001 & $2.7 \pm 0.7$ & $2.8 \pm 0.9$ & 2.03 & 0.043 \\
\hline apoA (g/L) & $1.5 \pm 0.3$ & $1.2 \pm 0.3$ & 15.31 & $<0.001$ & $1.6 \pm 0.2$ & $1.3 \pm 0.2$ & 14.22 & 0.009 \\
\hline аров (g/L) & $1.1 \pm 0.2$ & $0.9 \pm 0.3$ & 12.58 & $<0.001$ & $0.9 \pm 0.2$ & $0.9 \pm 0.3$ & 1.12 & $<0.001$ \\
\hline $\ln L p(a)$ & $5.3 \pm 1.0$ & $5.0 \pm 1.0$ & 4.34 & $<0.001$ & $5.3 \pm 1.0$ & $5.1 \pm 1.1$ & 2.62 & $<0.001$ \\
\hline InHCY & $2.4 \pm 0.5$ & $2.9 \pm 0.4$ & 18.63 & $<0.001$ & $1.9 \pm 0.6$ & $2.7 \pm 0.4$ & 21.34 & $<0.001$ \\
\hline InTBil & $2.6 \pm 0.4$ & $2.5 \pm 0.4$ & 5.92 & $<0.001$ & $2.5 \pm 0.3$ & $2.3 \pm 0.4$ & 4.93 & $<0.001$ \\
\hline InDBil & $1.3 \pm 0.4$ & $1.1 \pm 0.5$ & 4.91 & $<0.001$ & $1.1 \pm 0.4$ & $1.2 \pm 0.5$ & 1.66 & 0.097 \\
\hline InIBil & $2.3 \pm 0.4$ & $2.1 \pm 0.5$ & 7.04 & $<0.001$ & $2.1 \pm 0.4$ & $1.8 \pm 0.6$ & 8.21 & $<0.001$ \\
\hline InGGT & $3.7 \pm 0.8$ & $3.7 \pm 0.7$ & 0.86 & 0.391 & $2.8 \pm 0.7$ & $3.6 \pm 0.8$ & 12.93 & $<0.001$ \\
\hline
\end{tabular}

Normally distributed data were presented as means \pm SD, skewed data were logarithm transformed and presented as means \pm SD.

apoA, apolipoprotein A; apoB, apolipoprotein B; CHD, coronary heart disease; DBil, direct bilirubin; GGT, $\gamma$-glutamyl transpeptidase; HCY, homocysteine; HDL-C, high-density lipoprotein cholesterol; IBil, indirect bilirubin; LDL-C, low-density lipoprotein cholesterol; In, logarithm transformed; Lp(a), lipoprotein(a); TBil, total bilirubin; TC, total cholesterol; TG, triglyceride; UA, uric acid. 
not males and, conversely, $\ln \mathrm{DBil}$ is significantly associated with CHD in males but not females (table 2). Variables with $\mathrm{p}<0.10$ were included in a subsequent multiple logistic regression.

In view of the strong multicollinearity among three serum bilirubin indices (lnTBil, $\ln$ DBil and $\ln I B i 1)$, we used $\ln$ TBil exclusively to represent the serum bilirubin level and introduced the value into the multiple logistic regression model. There was also strong multicollinearity among three serum cholesterol indices (TC, HDL-C and LDL-C); thus, we computed the HDL-C and LDL-C ratio (HDL-C vs LDL-C) as a composite indicator for the multiple regression analysis.

Age, UA, TC, lnTG and HDL-C versus LDL-C, apoA, apoB, $\operatorname{lnLp}(\mathrm{a}), \ln \mathrm{HCY}$ and $\operatorname{lnTBil}$, were used to build the male model, while age, UA, TC, InTG and HDL-C versus LDL-C, apoA, apoB, $\operatorname{lnLp}(\mathrm{a}), \ln \mathrm{HCY}, \ln$ TBil and $\operatorname{lnGGT}$, were used to build the female model. The results of our backward stepwise selection process are listed in table 3; we found that increasing age, TC, $\operatorname{lnHCY}$ and $\operatorname{lnGGT}$, and decreasing UA, $\ln$ TG, apoA and apoB, increased the diagnosis of CHD in males. In comparison, increasing age, TC, lnHCY, lnGGT and HDL-C versus LDL-C and decreasing apoA, apoB, $\operatorname{lnLp}(\mathrm{a})$ and $\ln \mathrm{TBil}$, increased the diagnosis of CHD in females.

Probabilities of diagnosis of CHD for males and females were as following:

$$
\begin{aligned}
\text { Probability }\left(\mathrm{CHD}_{\text {male }}\right)= & 1 /\{1+\exp -(-6.91+0.11 \\
& \times \text { Age }-0.003 \times \mathrm{UA}+1.28 \\
& \times \mathrm{TC}-0.37 \times \mathrm{InTG}-5.42 \\
& \times \mathrm{apoA}-6.66 \times \mathrm{apoB}+2.66 \\
& \times \mathrm{InHCY}+1.07 \times \mathrm{InGGT})\},
\end{aligned}
$$

and

Probability $\left(\mathrm{CHD}_{\text {female }}\right)=1 /\{1+\exp -(-9.22+0.17$

$$
\begin{aligned}
& \times \text { Age }+1.39 \times \mathrm{TC}-7.38 \times \text { apoA } \\
& -1.77 \times \text { apoB }-0.39 \\
& \times \operatorname{InLp}(\mathrm{a})+2.98 \times \mathrm{InHCY} \\
& -1.75 \times \mathrm{InTBil}+0.89 \times \mathrm{InGGT} \\
& +4.74 \times \mathrm{HDL}-\text { Cvs.LDL }-\mathrm{C})\}
\end{aligned}
$$

\section{Discrimination of the screening models}

We evaluated the performance of the prediction models by drawing ROC curves of the CHD probabilities predicted by the above models and calculating the AUC. The AUC was 0.958 (95\% CI 0.946 to 0.969 ) for males and 0.986 (95\% CI 0.977 to 0.994 ) for females (figure 1, upper). The ROC curves showed that the sensitivity and specificity of the models were near optimal for males and females.

\section{Subjects included in the external validation population}

The data used for model validation were collected the following year; namely, 1 August 2013, to 31 July 2014. The model valid-

\begin{tabular}{|c|c|c|c|c|c|c|c|}
\hline \multirow[b]{2}{*}{ Predictor } & \multirow[b]{2}{*}{ B } & \multirow[b]{2}{*}{ SE } & \multirow[b]{2}{*}{ Wald } & \multirow[b]{2}{*}{ Significance } & \multirow[b]{2}{*}{ OR } & \multicolumn{2}{|c|}{$95 \% \mathrm{Cl}$ for OR } \\
\hline & & & & & & Lower & Upper \\
\hline \multicolumn{8}{|l|}{ Males } \\
\hline Age & 1.068 & 0.10 & 108.65 & $<0.001$ & 2.91 & 2.38 & 3.56 \\
\hline UA & -0.003 & 0.00 & 7.01 & 0.008 & 1.00 & 0.99 & 1.00 \\
\hline $\mathrm{TC}$ & 1.28 & 0.20 & 43.33 & $<0.001$ & 3.61 & 2.46 & 5.29 \\
\hline $\operatorname{lnTG}$ & -0.37 & 0.20 & 3.23 & 0.072 & 0.69 & 0.47 & 1.03 \\
\hline apoA & -5.42 & 0.52 & 108.39 & $<0.001$ & 0.00 & 0.00 & 0.01 \\
\hline apoB & -6.66 & 0.77 & 75.82 & $<0.001$ & 0.00 & 0.00 & 0.01 \\
\hline $\operatorname{lnHCY}$ & 2.66 & 0.33 & 66.53 & $<0.001$ & 14.22 & 7.51 & 26.91 \\
\hline $\operatorname{lnGGT}$ & 1.07 & 0.18 & 35.17 & $<0.001$ & 2.90 & 2.04 & 4.13 \\
\hline Constant & -6.91 & 1.28 & 29.24 & $<0.001$ & 0.00 & - & - \\
\hline \multicolumn{8}{|l|}{ Females } \\
\hline Age & 1.728 & 0.24 & 51.22 & $<0.001$ & 5.63 & 3.51 & 9.03 \\
\hline $\mathrm{TC}$ & 1.39 & 0.31 & 20.32 & $<0.001$ & 4.01 & 2.19 & 7.33 \\
\hline apoA & -7.38 & 1.24 & 35.35 & $<0.001$ & 0.00 & 0.00 & 0.01 \\
\hline apoB & -1.77 & 0.78 & 5.15 & 0.023 & 0.17 & 0.04 & 0.79 \\
\hline $\ln L p(a)$ & -0.39 & 0.22 & 3.15 & 0.076 & 0.68 & 0.44 & 1.04 \\
\hline InHCY & 2.98 & 0.50 & 36.37 & $<0.001$ & 19.76 & 7.49 & 52.10 \\
\hline InTBil & -1.75 & 0.58 & 9.04 & 0.003 & 0.17 & 0.06 & 0.55 \\
\hline $\operatorname{lnGGT}$ & 0.89 & 0.29 & 9.53 & 0.002 & 2.43 & 1.38 & 4.26 \\
\hline HDL-C vs LDL-C & 4.74 & 1.60 & 8.82 & 0.003 & 114.20 & 5.01 & 2603.02 \\
\hline Constant & -9.22 & 2.61 & 12.51 & $<0.001$ & 0.00 & - & - \\
\hline
\end{tabular}
ation population included 246 patients with CHD, with 176 males and 70 females, aged $61.8 \pm 11.1$ and $64.5 \pm 9.3$ years, respectively (table 4 ). The mean age (in years) of the control

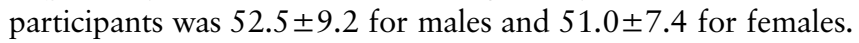

\section{External validation of the screening models}

To validate the above screening models, a separate population, identified the following year, was used. As described above, the model validation participants included 176 males and

Table 3 Predictors of CHD incidence by sex 


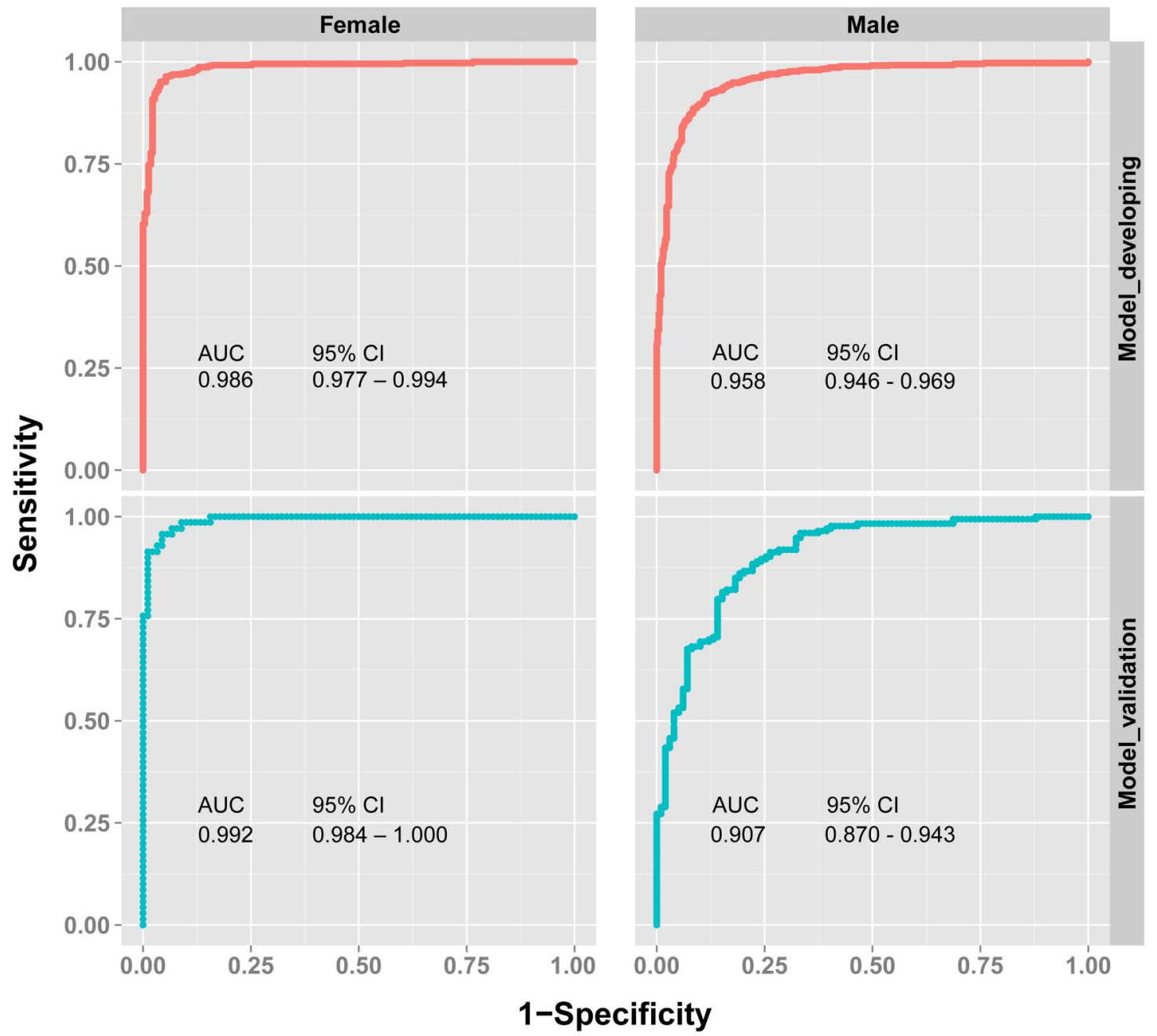

Figure 1 Performance and validation of the prediction models. The performance of discrimination was evaluated by ROC analyses, AUC and 95\% $\mathrm{Cl}$ were given for each ROC analysis. ROC, receiver operating characteristic; AUC, area under ROC curve (upper). The validation of the prediction models was also evaluated by ROC analyses, AUC and 95\% Cl were given for each ROC analysis. ROC, receiver operating characteristic; AUC, area under ROC curve (lower).

70 females with CHD confirmed by coronary angiography (table 4). We obtained each participant's probability of diagnosing with CHD using the above screening models. Next, ROC curves were plotted for both males and females (figure 1, Lower). The AUC for males $(0.907,95 \%$ CI 0.870 to 0.943 ) declined very slightly, while that for females $(0.992,95 \%$ CI 0.984 to 1.000 ) increased slightly, with no statistical significance.

\section{DISCUSSION}

To explore whether routine blood biochemical indices, together with age and sex, might be used to screen for suspected CHD in participants, we developed and externally validated screening models for males and females. Statistical analyses revealed that increasing age, TC, lnHCY and lnGGT, and decreasing UA, $\operatorname{lnTG}$, apoA and apoB, increased the detection probability of CHD in males. In comparison, increasing age, TC, lnHCY, lnGGT and HDL-C versus LDL-C, and decreasing apoA, apoB, $\operatorname{lnLp}(\mathrm{a})$ and $\operatorname{lnTBil}$, increased the diagnosis of CHD in females. ROC curves showed that the sensitivity and specificity of the models approached the optimum level in males and females. Both models were further externally validated in a separate population, with high performance. Several well-known risk factors for CHD, including age, TC, TG, apoA, apoB, HDL-C versus LDL-C, and HCY, were established as useful predictors of CHD in our screening model, while UA and TBil were also found to be predictors of CHD. In terms of UA, some studies have identified it as a risk factor for $\mathrm{CHD},{ }^{32}$ while other studies have shown that it is not a risk factor for CHD. ${ }^{39}$ These conflicting conclusions might be the result of a small sample size, unreasonable stratification, or inadequate statistical analysis. Although GGT, in clinical practice, is considered to be a biomarker for liver function, recent research has indicated that GGT is correlated with cardiovascular disease. ${ }^{40}$ Considering this fact, together with our data, the role of GGT in cardiovascular disease should be considered. Age, TC, HCY and GGT increased the risk of CHD, while apoA and apoB decreased the risk of CHD, although these factors had different coefficients among males and females in our screening models. UA and TG were found to be male-specific factors that decreased the risk of CHD; TBil and Lp(a) were found to be female-specific factors that decreased the risk of CHD, and HDL-C versus LDL-C was found to be a dominant factor increasing the risk of CHD. Further study is needed to determine why some risk factors are common to both sexes and why others are sex-specific.

Age, sex, family history and ethnicity are classic un-modifiable risk factors; hypertension, dyslipidaemia and diabetes, are 
Table 4 Description of the participants for model validation by gender

\begin{tabular}{|c|c|c|c|c|}
\hline \multirow[b]{2}{*}{ Variable } & \multicolumn{2}{|l|}{ Male } & \multicolumn{2}{|l|}{ Female } \\
\hline & $\begin{array}{l}\text { Control } \\
(n=99)\end{array}$ & $\begin{array}{l}\text { CHD } \\
(n=176)\end{array}$ & $\begin{array}{l}\text { Control } \\
(n=91)\end{array}$ & $\begin{array}{l}\text { CHD } \\
(n=70)\end{array}$ \\
\hline Age (year) & $52.5 \pm 9.2$ & $61.0 \pm 10.7$ & $51.0 \pm 7.4$ & $61.8 \pm 10.6$ \\
\hline $\mathrm{UA}(\mu \mathrm{mol} / \mathrm{L})$ & $395.3 \pm 80.3$ & $363.4 \pm 97.9$ & $297.0 \pm 74.3$ & $298.5 \pm 88.4$ \\
\hline $\mathrm{TC}(\mathrm{mmol} / \mathrm{L})$ & $4.7 \pm 0.8$ & $4.5 \pm 1.1$ & $4.7 \pm 0.7$ & $4.62 \pm 1.2$ \\
\hline $\mathrm{TG}(\mathrm{mmol} / \mathrm{L})$ & $1.8(1.2,2.6)$ & $1.7(1.3,2.4)$ & $1.3(1.0,2.0)$ & $1.8(1.4,2.9)$ \\
\hline $\mathrm{HDL}-\mathrm{C}(\mathrm{mmol} / \mathrm{L})$ & $1.4 \pm 0.3$ & $1.2 \pm 0.2$ & $1.6 \pm 0.3$ & $1.3 \pm 0.3$ \\
\hline LDL-C (mmol/L) & $2.9 \pm 0.8$ & $2.5 \pm 0.9$ & $2.9 \pm 0.6$ & $2.6 \pm 0.9$ \\
\hline ароA (g/L) & $1.5 \pm 0.2$ & $1.3 \pm 0.2$ & $1.7 \pm 0.2$ & $1.5 \pm 0.3$ \\
\hline аров (g/L) & $0.99 \pm 0.24$ & $1 \pm 0.23$ & $0.93 \pm 0.2$ & $0.97 \pm 0.29$ \\
\hline $\mathrm{Lp}(\mathrm{a})(\mathrm{mg} / \mathrm{L})$ & $188.0(85.0,373.0)$ & $297.0(140.0,433.0)$ & $163.0(81.0,327.0)$ & $248.0(98.0,470.0$ \\
\hline $\mathrm{HCY}(\mu \mathrm{mol} / \mathrm{L})$ & $10.3(8.5,12.8)$ & $14.5(11.9,19.0)$ & $6.4(5.3,7.8)$ & $11.6(9.0,13.7)$ \\
\hline TBil $(\mu \mathrm{mol} / \mathrm{L})$ & $13.4(10.7,16.5)$ & $14.2(11.2,19.3)$ & $10.8(8.7,13.1)$ & $12.8(10.4,17.7)$ \\
\hline Dbil $(\mu \mathrm{mol} / \mathrm{L})$ & $3.0(2.5,3.8)$ & $3.0(1.9,4.3)$ & $2.3(1.9,2.9)$ & $2.2(1.5,3.2)$ \\
\hline IBil $(\mu \mathrm{mol} / \mathrm{L})$ & $10.4(8.1,13.1)$ & $11.0(8.5,15.2)$ & $8.3(6.5,10.4)$ & $11.2(8.4,14.2)$ \\
\hline GGT (IU/L) & $27.0(17.0,47.0)$ & $35.0(22.0,79.0)$ & $18.0(12.0,25.0)$ & $25.0(16.0,44.0)$ \\
\hline
\end{tabular}

Normally distributed data were presented as means $\pm S D$, skewed data were presented as the median (IQR).

apoA, apolipoprotein $A$; apoB, apolipoprotein B; Bil, indirect bilirubin; CHD, coronary heart disease; DBil, direct bilirubin; GGT, $\gamma$-glutamyl transpeptidase; HCY, homocysteine; HDL-C, high-density lipoprotein cholesterol; LDL-C, low-density lipoprotein cholesterol; Lp(a), lipoprotein(a); TBil, total bilirubin; TC, total cholesterol; TG, triglyceride; UA, uric acid.

classic modifiable risk factors; and smoking, alcohol abuse, obesity and high dietary intake of high-fat, high-carbohydrate and high-calorie diets, are behavioural risk factors. ${ }^{17}$ Considering the many biomarkers identified thus far, ${ }^{17}$ the risk factors for CHD form an intricate network. To date, it has been impossible to integrate all of the complicated relationships existing among these risk factors to produce a single screening strategy with high performance in clinical practice. This difficulty is attributed to the present technological threshold of computational biology, the intrinsic complexity of the pathophysiological process, and interactions between host and risk factors. Also, our understanding of the physiological processes underlying the metabolic balance in humans remains limited. Although UA, TC, TG, HDL-C, LDL-C, apoA, apoB, Lp(a), HCY, TBil, DBil, IBil and GGT were found to be associated with CHD, ${ }^{17-40}$ most studies have focused on blood fat and HCY; few studies have tried to integrate these biomarkers to make a comprehensive correlation between them and CHD. In our statistical analysis, we did not include other known risk factors for CHD, including family history, hypertension, diabetes, smoking, alcohol abuse, obesity and high dietary intake of high-fat, high-carbohydrate and high-calorie diets. ${ }^{17}$ The reasons for this omission are as follows: the use of a questionnaire to obtain certain information (eg, family history and high dietary intake of high-fat, highcarbohydrate and high-calorie diets) was not considered to be reliable enough; smoking and alcohol abuse are difficult to

\section{What is already known on this subject}

Current cardiovascular risk-estimation systems include gender, age, smoking, cholesterol, systolic blood pressure etc, but neglect serum biochemical indices. Many serum biochemical indices, in addition to cholesterol, have been found to have changed with occurrence and developing of coronary heart disease; however, few studies have evaluated value of integrated biochemical indices on screening of coronary heart disease in suspected participants.

\section{What this study adds}

Statistical analyses revealed that increasing age, total cholesterol, homocysteine and $\gamma$-glutamyl transpeptidase, and decreasing uric acid, triglyceride, apoA and apoB, increased the diagnosis probability of coronary heart disease in males. Increasing age, TC total cholesterol, homocysteine, $\gamma$-glutamyl transpeptidase and high-density lipoprotein cholesterol versus low-density lipoprotein cholesterol, and decreasing apoA, аров, lipoprotein (a) and total bilirubin, increased the diagnosis of coronary heart disease in females. These models were further validated in an external validation population, with high performance.

quantify; the causal relationship between some risk factors and CHD remains undefined (eg, whether obesity is an independent risk factor for $\mathrm{CHD}$, a confounding factor, or a compensatory factor $)^{17}$; and current two-dimensional and three-dimensional analysis strategies cannot integrate all of the information effectively (ie, having more factors is not necessarily better).

\section{Author affiliations \\ ${ }^{1}$ Department of Laboratory, People's Hospital of Yuxi City, Yuxi, Yunnan Province, China \\ ${ }^{2}$ Department of Clinical Epidemiology \& Biostatistics, Peking University People's Hospital, Beijing, China \\ ${ }^{3}$ Intensive Care Unit, People's Hospital of Yuxi City, Yuxi, Yunnan Province, China ${ }^{4}$ Department of Cardiology, People's Hospital of Yuxi City, Yuxi, Yunnan Province, China \\ ${ }^{5}$ Department of the First General Surgery, People's Hospital of Yuxi City, Yuxi, Yunnan Province, China \\ ${ }^{6}$ Department of the Second General Surgery, People's Hospital of Yuxi City, Yuxi, Yunnan Province, China}

Contributors LF, JZ and LL designed the research; $C Z$ and SN performed the statistical analysis; LF and CZ wrote the paper; $\mathrm{YH}, \mathrm{WX}$ and $\mathrm{XZ}$ carried out the research.

Funding Yunnan Provincial Science and Technology Department of Basic Research on the Application of Self-Financing Projects 2013FZ257; the Regional Fund Project of the National Natural Science Foundation of China 81460326; the Scientific 
Research Fund of Yunnan Provincial Education Department 2011C083; Joint Special Funds from the Yunnan Province Science and Technology Department and Department of Applied Basic Research of Kunming Medical University $2013 F Z 283$.

Competing interests None declared.

Patient consent Obtained.

Ethics approval The Review Board of the People's Hospital of Yuxi City.

Provenance and peer review Not commissioned; externally peer reviewed.

Data sharing statement All data are included in the paper.

Open Access This is an Open Access article distributed in accordance with the Creative Commons Attribution Non Commercial (CC BY-NC 4.0) license, which permits others to distribute, remix, adapt, build upon this work non-commercially, and license their derivative works on different terms, provided the original work is properly cited and the use is non-commercial. See: http://creativecommons.org/ licenses/by-nc/4.0/

\section{REFERENCES}

1 Moran AE, Forouzanfar MH, Roth GA, et al. The global burden of ischemic heart disease in 1990 and 2010: the Global Burden of Disease 2010 study. Circulation 2014;129:1493-501.

2 Zhang XH, Lu ZL, Liu L. Coronary heart disease in China. Heart 2008:94:1126-31.

3 Camici PG, d'Amati G, Rimoldi O. Coronary microvascular dysfunction: mechanisms and functional assessment. Nat Rev Cardiol 2015;12:48-62.

4 Ross R. The pathogenesis of atherosclerosis: a perspective for the 1990s. Nature 1993:362:801-9.

5 Chilton RJ. Pathophysiology of coronary heart disease: a brief review. J Am Osteopath Assoc 2004;104(9 Suppl 7):S5-8.

6 Libby P, Theroux P. Pathophysiology of coronary artery disease. Circulation 2005; 111:3481-8.

7 Josephson M, Wellens HJ. Implantable defibrillators and sudden cardiac death. Circulation 2004; 109:2685-91.

8 Libby $\mathrm{P}$, Lichtman AH, Hansson GK. Immune effector mechanisms implicated in atherosclerosis: from mice to humans. Immunity 2013;38:1092-104.

9 Libby P, Ridker PM, Hansson GK. Progress and challenges in translating the biology of atherosclerosis. Nature 2011:473:317-25.

10 Libby P, Ridker PM, Hansson GK, Leducq Transatlantic Network on Atherothrombosis. Inflammation in atherosclerosis: from pathophysiology to practice. J Am Coll Cardiol 2009;54:2129-38.

11 Weber C, Zernecke A, Libby P. The multifaceted contributions of leukocyte subsets to atherosclerosis: lessons from mouse models. Nat Rev Immunol 2008;8:802-15.

12 Libby P. Inflammation in atherosclerosis. Arterioscler Thromb Vasc Biol 2012;32:2045-51.

13 Osterud B, Bjorklid E. Role of monocytes in atherogenesis. Physiol Rev 2003;83:1069-112

14 Tabas I. Nonoxidative modifications of lipoproteins in atherogenesis. Annu Rev Nutr 1999:19:123-39.

15 Demer LL. Vascular calcification and osteoporosis: inflammatory responses to oxidized lipids. Int J Epidemiol 2002:31:737-41.

16 Geng YJ, Libby P. Progression of atheroma: a struggle between death and procreation. Arterioscler Thromb Vasc Biol 2002;22:1370-80.

17 Lloyd-Jones DM. Cardiovascular risk prediction: basic concepts, current status, and future directions. Circulation 2010;121:1768-77.

18 Payne RA. Cardiovascular risk. Br J Clin Pharmacol 2012;74:396-410.

19 Anderson KM, Wilson PW, Odell PM, et al. An updated coronary risk profile. A statement for health professionals. Circulation 1991;83:356-62.
20 Lerner DJ, Kannel WB. Patterns of coronary heart disease morbidity and mortality in the sexes: a 26-year follow-up of the Framingham population. Am Heart J 1986;111:383-90.

21 Chow CK, Islam S, Bautista L, et al. Parental history and myocardial infarction risk across the world: the INTERHEART Study. J Am Coll Cardiol 2011;57: 619-27.

22 Forouhi NG, Sattar N. CVD risk factors and ethnicity-a homogeneous relationship? Atheroscler Supp/ 2006:7:11-19.

23 Lewington S, Clarke R, Qizilbash N, et al, Prospective Studies Collaboration. Age-specific relevance of usual blood pressure to vascular mortality: a meta-analysis of individual data for one million adults in 61 prospective studies. Lancet 2002;360:1903-13.

24 Collins R, Peto R, MacMahon S, et al. Blood pressure, stroke, and coronary heart disease. Part 2, Short-term reductions in blood pressure: overview of randomised drug trials in their epidemiological context. Lancet 1990;335:827-38.

25 Yusuf S, Hawken S, Ounpuu S, et al. Effect of potentially modifiable risk factors associated with myocardial infarction in 52 countries (the INTERHEART study): case-control study. Lancet 2004;364:937-52.

26 Selvin E, Marinopoulos S, Berkenblit G, et al. Meta-analysis: glycosylated hemoglobin and cardiovascular disease in diabetes mellitus. Ann Intern Med 2004; 141:421-31.

27 Stratton IM, Adler Al, Neil HA, et al. Association of glycaemia with macrovascular and microvascular complications of type 2 diabetes (UKPDS 35): prospective observational study. BMJ 2000;321:405-12.

28 Yayan J. Emerging families of biomarkers for coronary artery disease: inflammatory mediators. Vasc Health Risk Manag 2013;9:435-56.

29 Wierzbicki AS. New directions in cardiovascular risk assessment: the role of secondary risk stratification markers. Int J Clin Pract 2012;66:622-30.

30 McCullough PA, Verrill TA. Cardiorenal interaction: appropriate treatment of cardiovascular risk factors to improve outcomes in chronic kidney disease. Postgrad Med 2010;122:25-34.

31 Veeranna V, Zalawadiya SK, Niraj A, et al. Homocysteine and reclassification of cardiovascular disease risk. J Am Coll Cardiol 2011;58:1025-33.

32 Feig DI, Kang DH, Johnson RJ. Uric acid and cardiovascular risk. N Eng/ J Med 2008:359:1811-21.

33 Lassus J, Harjola VP. Cystatin C: a step forward in assessing kidney function and cardiovascular risk. Heart Fail Rev 2012;17:251-61.

34 Cerasola G, Cottone $S$, Mulè $G$. The progressive pathway of microalbuminuria: from early marker of renal damage to strong cardiovascular risk predictor. J Hypertens 2010;28:2357-69.

35 D'Agostino RB Sr, Vasan RS, Pencina MJ, et al. General cardiovascular risk profile for use in primary care: the Framingham Heart Study. Circulation 2008;117:743-53.

36 Ridker PM, Buring JE, Rifai N, et al. Development and validation of improved algorithms for the assessment of global cardiovascular risk in women: the Reynolds Risk Score. JAMA 2007:297:611-19.

37 Assmann G, Cullen P, Schulte H. Simple scoring scheme for calculating the risk of acute coronary events based on the 10-year follow-up of the prospective cardiovascular Münster (PROCAM) study. Circulation 2002;105:310-15.

38 Conroy RM, Pyörälä K, Fitzgerald AP, et al, SCORE Project Group. Estimation of ten-year risk of fatal cardiovascular disease in Europe: the SCORE project. Eur Heart J 2003;24:987-1003.

39 Persky VW, Dyer AR, Idris-Soven $\mathrm{E}$, et al. Uric acid: a risk factor for coronary heart disease? Circulation 1979;59:969-77

40 Celik O, Cakmak HA, Satilmis S, et al. The relationship between gamma-glutamyl transferase levels and coronary plaque burdens and plaque structures in young adults with coronary atherosclerosis. Clin Cardiol 2014;37:552-7. 